\title{
Residual Stress in Focused Charged Particle Beam-Deposited Materials
}

Gavin Mitchson ${ }^{*}$, Andrew Clarke ${ }^{1}$, and Jamie Johnson ${ }^{1}$

1. Thermo Fisher Scientific, Materials and Structural Analysis Division, Hillsboro, OR USA. *Corresponding author: Gavin.Mitchson@ThermoFisher.com

Deposition of materials onto a surface through focused charged particle beam-induced local decomposition of adsorbed precursor molecules is foundational for many additive focused charged particle beam applications, including nanoprototyping and transmission electron microscope (TEM) lamella preparation [1]. Although there are a few reports investigating the composition and mechanical properties of various materials deposited primarily using $\mathrm{Ga}^{+}-\mathrm{FIB}$ induced deposition [2-4], there is scant work evaluating the residual stress as a function of deposition conditions (charged particle species, accelerating voltage, beam current, growth rate, etc.). This information will be critical for achieving success with non-Ga+ $\mathrm{GIB}^{+}$in nanoprototyping and TEM lamella preparation applications. Herein, we report our observations of residual stress in materials deposited using the electron beam, $\mathrm{Ga}^{+}-\mathrm{FIB}$, and $\mathrm{Xe}^{+}$-FIB and attempts to quantify the residual strain in these materials.

Figure 1 is a tableau of scanning electron micrographs acquired of various beam-deposited materials deposited as a rectangle under different conditions onto a thin silicon nitride membrane. Each rectangle was milled on three sides using the focused ion beam to form a cantilever (one short side uncut), which could then deflect in response to the residual stress in the deposited material. Qualitatively, the $\mathrm{Xe}^{+}-$ deposited materials induce substantially greater cantilever deflections relative to their $\mathrm{Ga}^{+}$-deposited counterparts. This is consistent with observations from our TEM lamella prep efforts. A carbon over

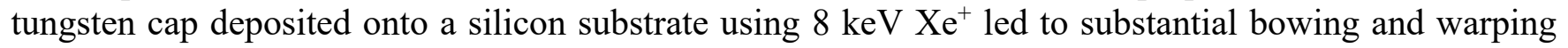
of the lamella (Figure 2). The lamella was over $100 \mathrm{~nm}$ thick, significantly thicker than those routinely prepared without any visible warping using an analogously structured cap with $\mathrm{Ga}^{+}-\mathrm{FIB}$ deposited materials. Without alteration of the capping structure, this implies that residual stress in the beamdeposited capping layers may fundamentally limit the minimum lamella thickness achievable.

While the cantilever experiments demonstrate a clear difference in the residual stress between $\mathrm{Ga}^{+}$-FIB and $\mathrm{Xe}^{+}$-FIB deposited materials, they do not readily permit quantification of the residual stress in these materials. To that end, we have pursued a FIB milling and digital image correlation (DIC) technique, similar to that described in Refs. [5], [6], to quantify the residual strain in these materials as a function of deposition conditions. The important parameters we have identified so far include ion species $\left(\mathrm{Ga}^{+}\right.$or $\mathrm{Xe}^{+}$) and accelerating voltage. Growth rate (controlled via current density) appears to have minimal impact on residual strain, as illustrated in Figure 3 for $\mathrm{Xe}^{+}$-PFIB deposited $\mathrm{C}$ and W. In general, there is more residual strain present in $\mathrm{Xe}^{+}$-deposited material than in $\mathrm{Ga}^{+}$-deposited material. Additionally, decreasing the beam accelerating voltage (for both $\mathrm{Ga}^{+}$and $\mathrm{Xe}^{+}$) leads to increased residual strain. Further work is needed to understand the origins of residual stress in focused charged particle beamdeposited material and to characterize residual stress from other non- $\mathrm{Ga}^{+}$and non-Xe $\mathrm{e}^{+}$ion species [7].

\section{References:}

[1] I Utke, P Hoffmann, and J Melngailis, J. Vac. Sci. Technol. B 26 (2008), p. 1197.

[2] S Reyntjens and R Puers, J. Micromech. Microeng. 10 (2000), p. 181. 
[3] S Okada et al, Japanese J. Appl. Physics 45 (2006), p. 5556.

[4] J Igaki et al., J. Vac. Sci. Technol. B 24 (2006), p. 2911.

[5] AM Korsunsky, M Sebastiani, and E Bemporad, Surf. Coatings Technol. 205 (2010), p. 2393.

[6] X Song et al., Thin Solid Films 520 (2012), p. 2073.

[7] The authors thank Chad Rue and Tom Miller for their insights and conversations during this work.
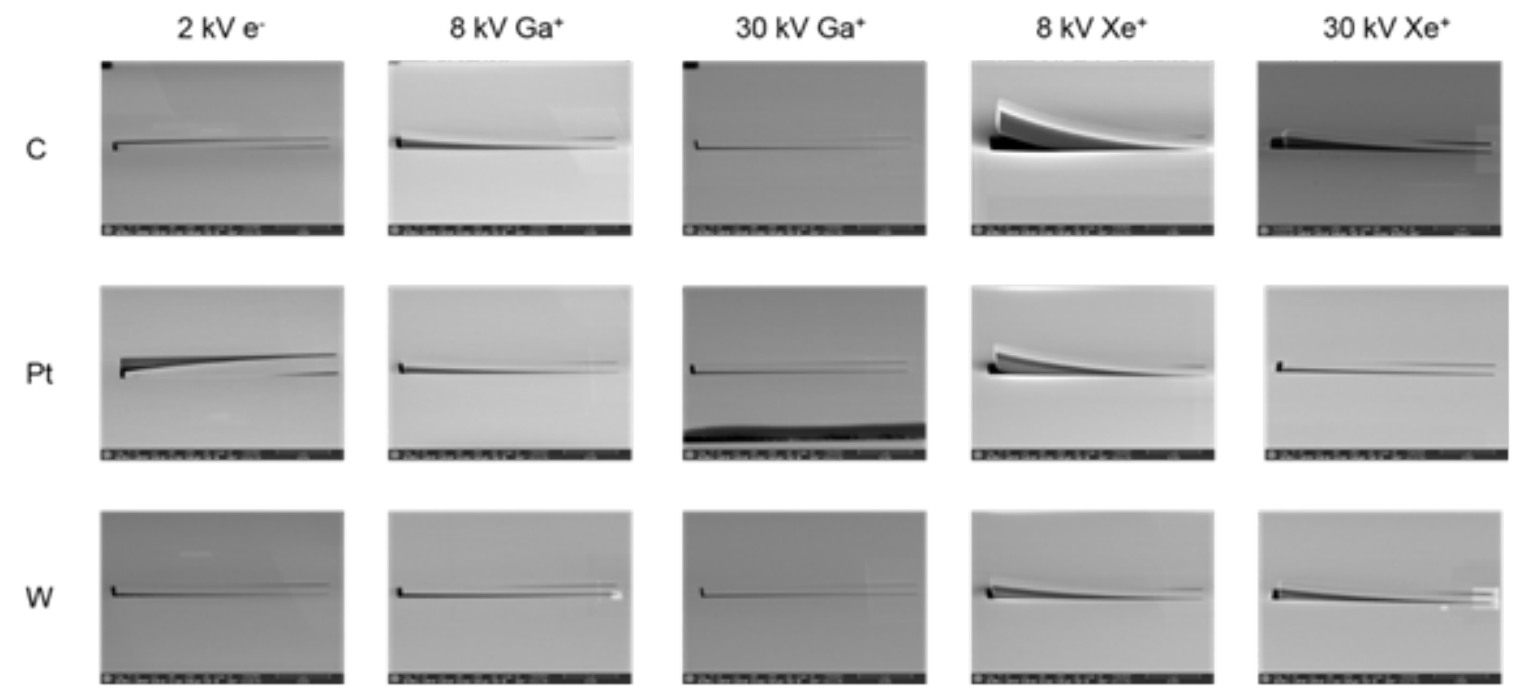

Figure 1. Tableau of SEM micrographs illustrating silicon nitride cantilever deflection as a function of deposited material, charged particle species, and accelerating voltage. The uncoated silicon nitride membrane surface is "up" in these images, with the deposited material on the "underside."

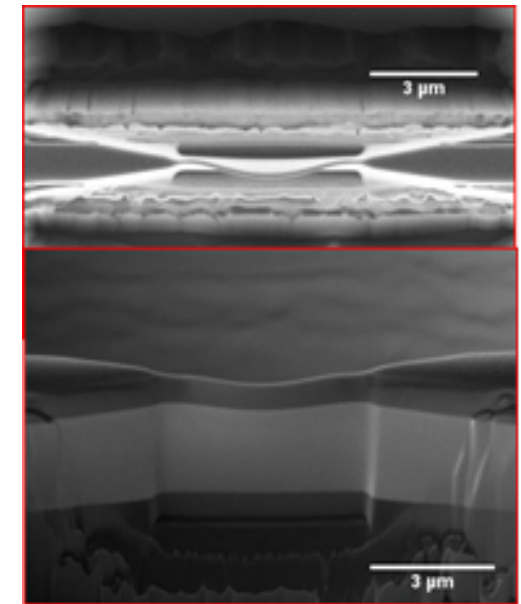

Figure 2. Top-down and side-view $\left(45^{\circ}\right.$ incidence) SEM micrographs of a visibly-warped lamella prepared from bare Si using a W/C bilayer protective cap deposited with $8 \mathrm{keV} \mathrm{Xe}{ }^{+}$ions.

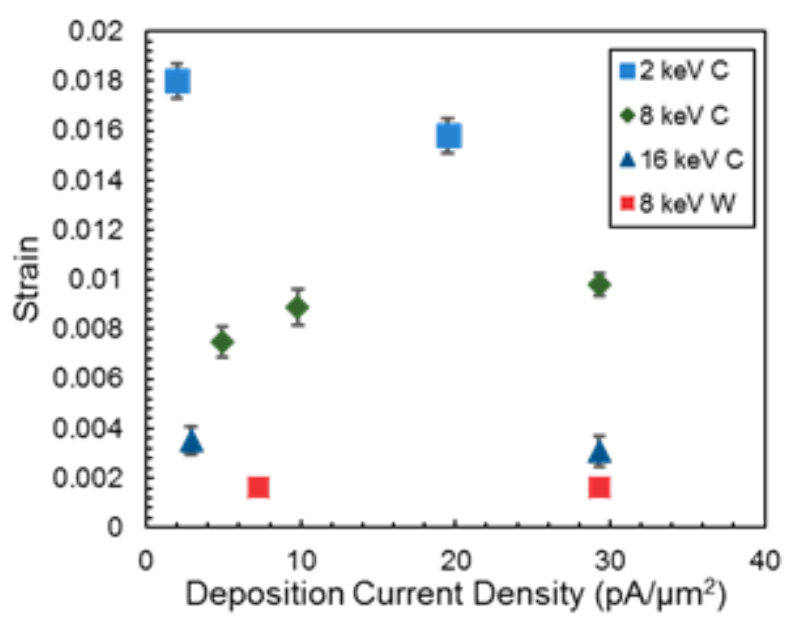

Figure 3. Residual strain values for $\mathrm{Xe}^{+}-\mathrm{PFIB}$ deposited materials measured using the ring milling and digital image correlation technique as a function of current density by beam energy and material type. 